\title{
Simple design method for detached house on liquefied ground
}

\author{
H. Yokawa ${ }^{\text {i) }}$, A. Yashima ${ }^{\text {ii) }}$, T. Sugii iii) ${ }^{\text {ii }}$ K. Yamada ${ }^{\text {iv) }}$, N. Asano ${ }^{\text {v) }}$ and T. Yoshihara ${ }^{\text {vi) }}$ \\ i) Assistant Professor, Department of Civil Engineering, Chubu University, 1200 Matsumoto-cho, Kasugai, Aichi 487-8501, Japan. \\ ii) Professor, Department of Civil Engineering, Gifu University, 1-1 Yanagido, Gifu, Gifu 501-1193, Japan. \\ iii) Professor, Department of Civil Engineering, Chubu University, 1200 Matsumoto-cho, Kasugai, Aichi 487-8501, Japan. \\ iv) Professor, Department of Civil Engineering, Chubu University, 1200 Matsumoto-cho, Kasugai, Aichi 487-8501, Japan. \\ v) Technical assistant, Department of Civil Engineering, Chubu University, 1200 Matsumoto-cho, Kasugai, Aichi 487-8501, Japan. \\ vi) Graduate Student, Department of Civil Engineering, Gifu University, 1-1 Yanagido, Gifu, Gifu 501-1193, Japan.
}

\begin{abstract}
Damages to detached houses, including settlement and tilting, were reported as a result of the 2011 off the Pacific coast of Tohoku Earthquake. Because liquefaction countermeasures usually employed for public works were expensive, common liquefaction countermeasures were difficult to apply to detached houses and a clear design method for the ground improvement against liquefaction has not seen in the Building Standards Law, the effective ground treatment has not been carried out to detached houses. In this study, for detached houses, in order to propose a simplified design method capable of predicting the settlement and tilting of the houses, model shaking table tests and numerical simulation are carried out. As the result, in this paper, the following conclusions are obtained.

1. Terzaghi's ultimate bearing capacity can be calculated using circular slip method.

2. The numerical analyses are found to be able to reproduce the experimental results very well.

3. In the simple design method, regardless of the friction angle, the excess pore water pressure ratio is lower, the higher the safety factor is. Furthermore the water lever is deeper, the higher the safety factor is.
\end{abstract}

Keywords: liquefaction, detached house, design method, model test, numerical analysis

\section{INTRODUCTION}

Liquefaction has been reported in a large-scale earthquake. In the 2011 off the Pacific coast of Tohoku Earthquake on March 11, 2011, serious damages, such as tilting and settlement in small buildings such as detached houses were seen over a wide area ${ }^{1)}$. One of the reasons is that countermeasures widely applied to public works have not been used to detached houses due to high cost.

In addition, the design method for a liquefaction-prone ground was not seen in the Japanese Building Standards Law. When the ground liquefaction is expected, the pile foundation is usually employed. We are trying to prevent the ground liquefaction completely by the pile foundation.

In this study, for detached houses, in order to propose a simplified design method capable of predicting the settlement and tilting of the houses, model shaking table tests and numerical simulation are carried out.

\section{SIMPLE DESIGN METHOD}

We propose a simple design method using a circular slip method and $F_{L}$ value. Simple design method proposed is based on the factor of safety by the balance between the resistance force of the soil and sliding force by housing self-weight at the circular slip surface. When the factor of safety is 1.0 , the load indicates the ultimate bearing capacity. In order to take the liquefaction into consideration to stability analysis, the resistance of the soil is reduced according to the pore water pressure generation.

A design method using circular slip method can take the increase in the strength of soil beneath the detached house in to consideration by a ground improving technique. On the other hand, the practical design method commonly used can't treat the partial improvement effect.

\subsection{Calculation of simple design method}

Fig.1 shows the assumed slip lines of Terzaghi (solid line) and assumed slip lines in the circular slip method (dashed line). The assumed circular slip line shown in Fig. 1 passes through the point a and point e which are on the Terzaghi's slip line. The deepest point of the assumed slip line coincides with the depth of point c on Terzaghi's slip line. Equation (1) shows the factor of safety by Terzaghi's method. In Equation (2), the pore water pressure is taken into consideration. When the ground once liquefies, the cohesion $c$ can be neglected. Under the liquefaction condition, the factor 
of safety shown in Equation (3) is derived.

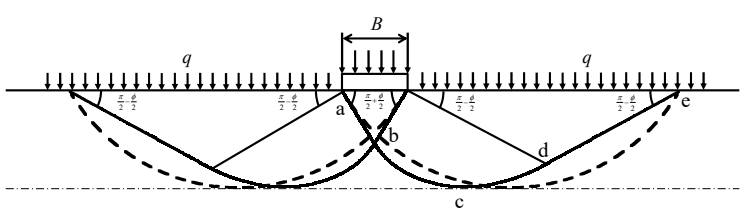

Fig.2. Failure surface of Terzaghi's Bearing Capacity theory

$$
\begin{gathered}
F_{S}=\frac{\sum\left[W_{i} \cos \alpha_{i} \tan \phi_{i}+c_{i} l_{i}\right]}{\sum W_{i} \sin \alpha_{i}} \\
F s=\frac{\sum\left[\left(W_{i}^{\prime} \cos \alpha_{i}-u l\right) \tan \phi_{i}+c_{i} l_{i}\right]}{\sum W_{i}^{\prime} \sin \alpha_{i}} \\
F_{S}=\frac{\sum\left[\left(W_{i}^{\prime} \cos \alpha_{i}-u l\right) \tan \phi_{i}\right]}{\sum W_{i}^{\prime} \sin \alpha_{i}}
\end{gathered}
$$

In the equations, $F \mathrm{~s}$ is the factor of safety, $W$ is the mass of soil blocks, $\alpha$ is the angle of slip surface, $\phi$ is the internal friction angle, $c$ is the cohesion, $u$ is the pore water pressure and $l$ is the length of circular slip.

The bearing capacities are calculated by proposed method and Terzaghi's method with different internal friction angle. Table 1 shows parameters for the proposed method. Fig. 2 shows the result of calculations. From Fig.1, it is found that the proposed method is able to reproduce the Terzaghi's bearing capacity.

Table 1. Parameters used in the proposed method

\begin{tabular}{ll|l}
\hline width of foundation & $B$ & $8.0(\mathrm{~m})$ \\
\hline depth of the foundation & $D_{\mathrm{f}}$ & $0.0(\mathrm{~m})$ \\
\hline angle of load from vertical & $\theta$ & $0.0(\mathrm{deg})$ \\
\hline unit weight of soil & $\gamma_{\mathrm{t}}$ & $18.0\left(\mathrm{kN} / \mathrm{m}^{3}\right)$ \\
\hline unit cohesion of soil & $c$ & $0.0(\mathrm{kPa})$ \\
\hline
\end{tabular}

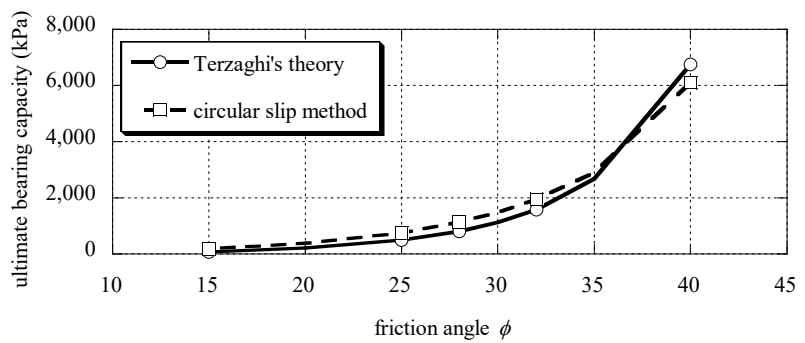

Fig.2. Variation of ultimate bearing capacity with respect to the friction angle

\section{MODEL SHAKING TABLE TEST}

In order to investigate the settlement of a detached house and the deformation of the ground during liquefaction, shaking table tests are carried out by using the soil container as shown in Fig.3). The experimental scale is $1 / 50$ of real condition. In the experiment, a small camera is installed on the soil tank in order to check the settlement of house or ground deformation during liquefaction. In addition, a variety of measuring instruments are placed in the ground in order to capture the pore pressure generation and acceleration time history.

\subsection{Experimental conditions}

The relative density is targeted to $50 \%$ in the experiment. The Mikawa silica sand No. 6 are used. The dry sand is dropped into the water to make $450 \mathrm{~mm}$ high model ground.

Housing model is made of acrylic box and the aluminum plate. Aluminum plate is added to adjust the housing weight equivalent to the contact ground pressure generally appeared for the wooden house $\left(0.3 \mathrm{kN} / \mathrm{m}^{2}\right)$.

Sinusoidal input motion is adopted in experiment. Frequency, maximum acceleration and duration time are set to $2 \mathrm{~Hz}, 350$ gal and 15 seconds. The time history of the acceleration obtained from the accelerometer attached to the shaking table is shown in Fig.5.

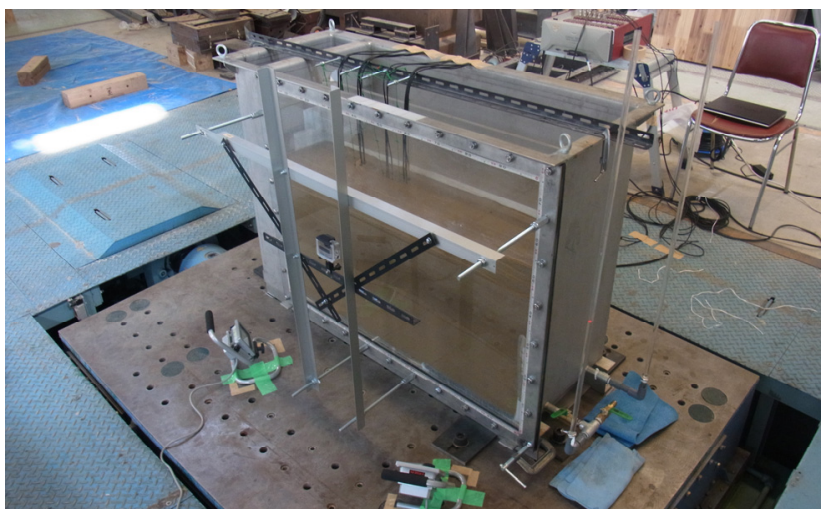

Fig.3. Experimental configuration

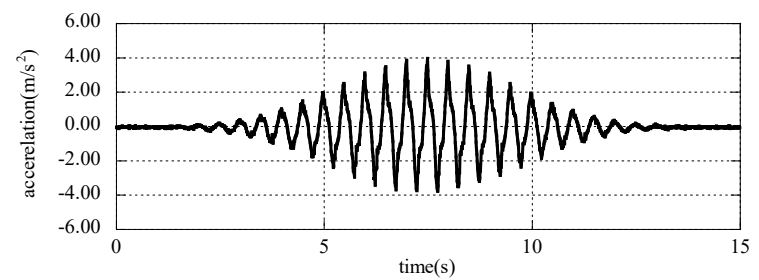

Fig.4. Input motion

\section{NUMERICAL SIMULARIONS}

The two-dimensional effective stress analysis program LIQCA2D14 ${ }^{2)}$ is used to reproduce the model shaking table tests described in the previous section. After confirming the reproducibility of the simulation, the details of the pore water pressure generation and the settlement of house are discussed.

\subsection{Condition of simulations}

Fig.5 shows the finite element mesh used in the numerical simulations. The number of nodes and elements used are 1,125 and 1,040 respectively. As boundary condition of the displacement, the bottom surface is fixed in the horizontal (x), vertical (y), and rotational directions. The lateral boundary is fixed in the horizontal direction (x). 
Parameters of elasto-plastic constitutive model are determined from previous studies ${ }^{3)}$. Table 2 shows parameters for liquefaction-prone ground. Fig.6 compares the liquefaction strengths obtained by model simulations and cyclic triaxial tests.

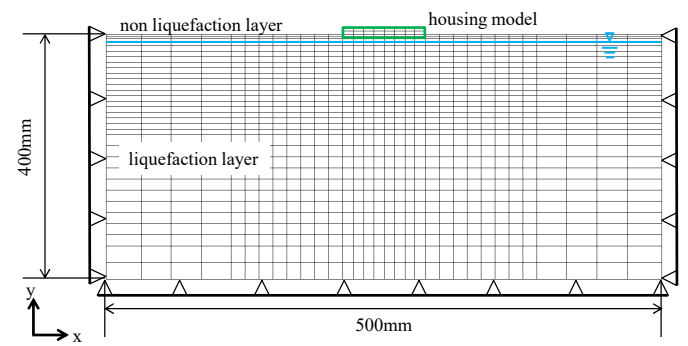

Fig.5. Finite element mesh

Table 2 Parameters for liquefaction-prone ground

\begin{tabular}{lc|c}
\hline Initial void ratio & $e_{0}$ & 0.802 \\
\hline Compression index & $\lambda$ & 0.050 \\
\hline Swelling index & $\kappa$ & 0.006 \\
\hline Quasi-over consolidation ratio & $O C R^{*}$ & 1.7 \\
\hline Initial shear modulus ratio & $G_{\sigma} \sigma^{\prime}{ }_{m}$ & 687.5 \\
\hline Failure stress ratio & $M^{*}{ }_{f}$ & 1.222 \\
\hline Phase transformation stress ratio & $M^{*}{ }_{m}$ & 0.682 \\
\hline Hardening function parameters & $B^{*}{ }_{0}$ & 1,300 \\
\cline { 2 - 3 } & $B^{*}{ }_{l}$ & 70 \\
\hline Referential strain parameters & $P^{*}{ }_{r}$ & 0.010 \\
\cline { 2 - 3 } & $F^{*}{ }_{r}$ & 0.030 \\
\hline Dilatancy coefficient parameters & $D^{*}{ }_{0}$ & 5.0 \\
\cline { 2 - 3 } & $n$ & 3.7 \\
\hline
\end{tabular}

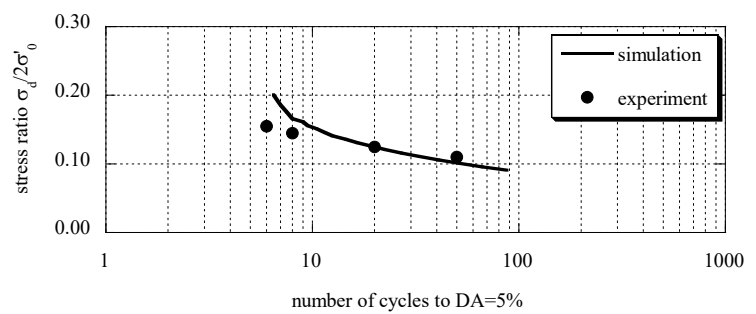

Fig.6. Liquefaction strength curve

\subsection{Results of numerical simulation}

Fig. 7 shows time histories of acceleration, pore water pressure and house settlement from experiment and simulation. Shaking table test results are plotted by thin lines and simulated results are shown by thick lines. The time history of acceleration is found to be slightly underestimated after liquefaction by the simulation. On the other hand, initial generation of pore water pressure is faster in the simulation than in the experiment. The overall time history of the pore water pressure in the experiment is approximately reproduced by the simulation.

As far as the settlement of the house concerned, the rate of the settlement is slower in the simulation than in the experiment. On the other hand, the final settlement is slightly overestimated about $10 \%$ compared to the experimental one. Fig. 8 shows the final deformation of the ground.
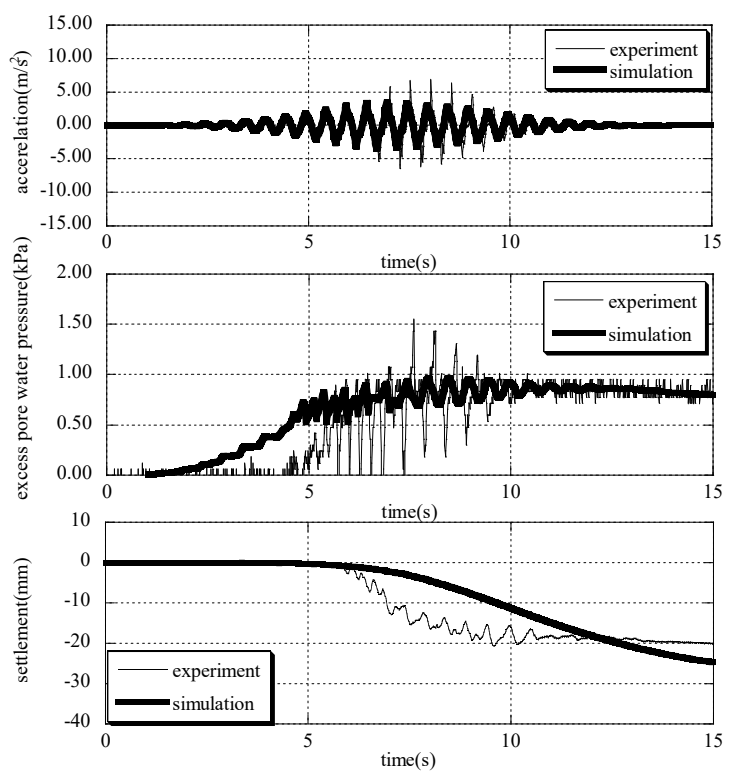

Fig.7. Time histories of acceleration, pore water pressure and house settlement

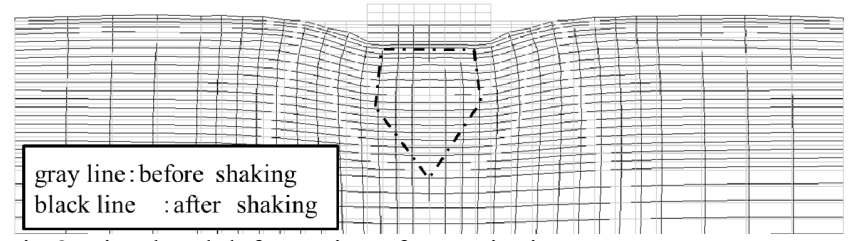

Fig.8. Simulated deformation after excitation

The two-dimensional effective stress analysis program LIQCA2D is used to reproduce the model shaking table tests. The results obtained are summarized as follows;

- The simulation reproduces approximately time histories of acceleration, pore water pressure and house settlement obtained in the experiment.

- The wedge shaped deformation pattern is obtained just beneath the house after the shaking which is also observed in the experiment. This means that the failure surface assumed in Fig. 2 is considered to be effective to investigate the stability of the detached house on the liquefied ground.

\section{ADAPTABILITY OF PROPOSED METHOD}

The applicability of the proposed method is discussed based on the comparison between the numerical results introduced in the previous section and the parametric studies by the proposed method..

\subsection{Parametric studies by LIQCA}

Parametric studies are carried out using same soil parameters in section 4.1. On the other hand, ground water level is changed to GL. $-1.0 \mathrm{~m}$ from GL. $-5.0 \mathrm{~m}$. Table 4 shows the variation of ground water level considered. Fig.9 shows results of deformation and distribution of excess pore water pressure after the 
excitation. As shown in Fig.9, the deeper the ground water level from the ground surface is, the smaller the settlement of the house is.

Table 4. Condition of case studies

\begin{tabular}{l|l}
\hline case & water revel \\
\hline case 1 & GL. $-1.0 \mathrm{~m}$ \\
\hline case2 & GL. $-2.0 \mathrm{~m}$ \\
\hline case3 & GL.-3.0m \\
\hline case4 & GL.-4.0m \\
\hline case5 & GL.-5.0m \\
\hline
\end{tabular}
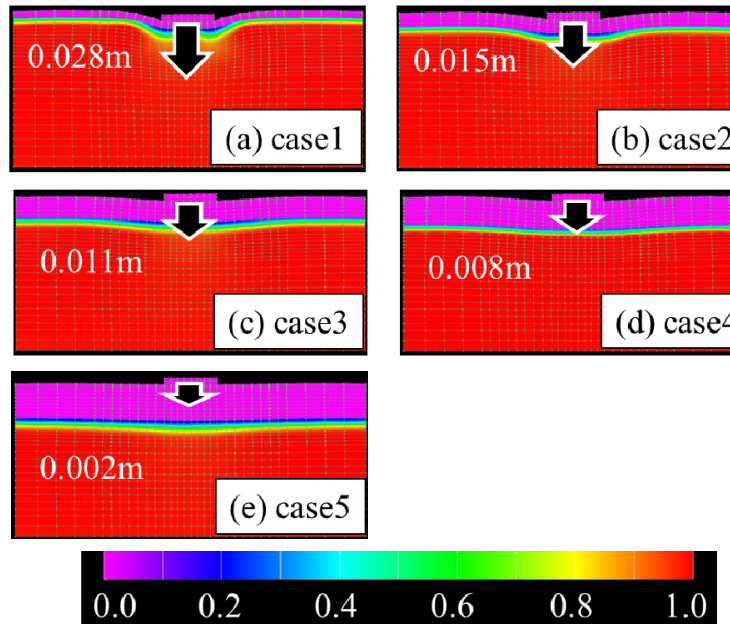

Fig.9. Deformation and distribution of excess pore water pressure after excitation

\subsection{Parametric studies by the proposed method}

The damage certification due to the disaster by the Cabinet Office is judged based on the amount of tilt of the house after liquefaction. In this study, the amount of tilt of the house is calculated by the survey report by Kim, et al. ${ }^{4)}$ obtained the Great East Japan Earthquake. The report summarized the linear relationship between the relative settlement amount and the amount of tilt. The amount of tilt of the house is calculated using the relative settlement obtained in the previous section.

The analytical parameters used in the proposed method are summarized in Table 5. Table 6 summarizes the relationship between safety factor obtained by the proposed method and the grade of damage calculated by LIQCA.

Table 5. Analytical parameters

\begin{tabular}{lc|l}
\hline width of foundation & $B$ & $7.5(\mathrm{~m})$ \\
\hline depth of the foundation & $D_{\mathrm{f}}$ & $0.0(\mathrm{~m})$ \\
\hline angle of load from vertical & $\theta$ & $0.0(\mathrm{deg})$ \\
\hline unit weight of soil & $\gamma_{\mathrm{t}}$ & $18.3\left(\mathrm{kN} / \mathrm{m}^{3}\right)$ \\
\hline effective unit weight of soil & $\gamma^{\prime}$ & $9.0\left(\mathrm{kN} / \mathrm{m}^{3}\right)$ \\
\hline friction angle & $\phi$ & $25(\mathrm{deg})$ \\
\hline unit cohesion of soil & $c$ & $0.0(\mathrm{kPa})$ \\
\hline
\end{tabular}

Table 6. Relationship between safety factor and grade of damage

\begin{tabular}{l|c|c|c|l}
\hline & $\begin{array}{l}\text { Settlement(m) } \\
\text { Full-scale in }\end{array}$ & $\begin{array}{l}\text { Inclination } \\
(/ 1,000)\end{array}$ & Safety factor & Damage grade \\
\hline case1 & 1.40 & 120 & $0.00(-0.42)$ & completely destroyed \\
\hline case2 & 0.75 & 65 & $0.00(-0.36)$ & completely destroyed \\
\hline case3 & 0.55 & 47 & 0.32 & large-scale partially destroyed \\
\hline case4 & 0.40 & 35 & 1.06 & large-scale partially destroyed \\
\hline case5 & 0.10 & 9 & 2.41 & partially injured \\
\hline
\end{tabular}

\section{CONCLUSIONS}

. In this study, for detached houses, in order to propose a simplified design method capable of predicting the settlement and tilting of the houses, model shaking table tests and numerical simulation are carried out. The results obtained are summarized.

- The proposed method by using the circular slip surface predicts the bearing capacity by Terzaghi's method approximately.

- The two-dimensional effective stress analysis program LIQCA can reproduce the model shaking table test results quantitatively.

- In the simple design method, it is found that the deeper the ground water level from the ground surface is, the higher the factor of safety is. From this consideration, there is a possibility to predict the grade of damage of the detached house on the liquefied ground by the proposed simple method. At the same time, the proposed method has a great advantage in taking the effect of ground improvement into consideration.

\section{REFERENCES}

1) Tokimatsu, K. et al. (2012): Liquefaction -induced Damage to buildings in Urayasu City During The 2011 Tohoku Pacific Earthquake, Proc. of the International Symposium on Engineering Lessons Learned from the 2011 Great East Japan Earthquake, pp.665-674.

2) Oka, F. et al. (1999): A cyclic elasto-plastic constitutive model for sand considering a plastic-strain dependence of the shear modulus, Geotechnique, Vol. 49, No. 5, pp. 661-680.

3) Nakai, K. (2009):: Structure upgradation concept applied to cyclic mobility of sand and high ductility of natural clay, Proceedings of 17 th International Conference on Soil Mechanics and Geotechnical Engineering, Alexandria (Egypt), pp.175-178.

4) Kim, C. et al. (2012): Damage of Foundation for Detached Houses in Liquefied Areas by the Tohoku Region Pacific Coast Earthquake, Japanese Geotechnical Journal, Vol. 7 , No. 1, pp.195-205. 